\title{
Atypical case of acute coronary syndrome due to coronary-pulmonary steal syndrome secondary to pulmonary embolism
}

\author{
Christian Mongiardi • Francesco Dentali • Walter Ageno • \\ Andrea Maria Maresca $\cdot$ Alessandro Squizzato • \\ Andrea Bertolini $\cdot$ Edoardo Verna $\cdot$ Achille Venco
}

Received: 23 August 2010/Accepted: 23 November 2010/Published online: 14 December 2010

(c) SIMI 2010

\section{Case presentation}

Dr. Mongiardi, Dr. Maresca: G.L. is a 64-year-old man on chronic oxygen therapy due to chronic obstructive pulmonary disease (COPD) in the setting of a bronchiectasic disease, referred to our hospital in September 2009 because of a micturition-nocturnal-syncope preceded by dizziness. The patient had neither a personal history of coronary artery disease nor known cardiovascular risk factors. In the emergency department (ED) the patient presented preserved consciousness and mild dyspnea despite low flows of inhalatory $\mathrm{O}_{2}(2 \mathrm{l} / \mathrm{min})$; chest examination was characterized by sibilant and sonorous rales in addition to bibasilar thin crackles; hemo-gas analysis (HGA) showed severe hypoxemic-hypercapnic acidosis (pH 7.18, $\mathrm{pCO}_{2} 85 \mathrm{mmHg}, \mathrm{pO}_{2} 58 \mathrm{mmHg}, \mathrm{sO}_{2} 84 \%$, $\left.\mathrm{HCO}_{3}{ }^{-} 23.5,5\right)$; the ECG demonstrated sinus tachycardia, mild and non-specific ST segment elevation V1-V3; the chest X-ray study showed a COPD pattern, right-basal paracardiac radio-opacity, enlargement of the left cardiac chambers. Blood tests demonstrated a leukocytosis with a mild elevation of LDH and D-Dimer [WBC 19,860, $\mathrm{Hb} 13.4 \mathrm{~g} / \mathrm{dL}$, creatinine $0.85 \mathrm{mg} / \mathrm{dL}$, troponin $\mathrm{I}\left(\mathrm{T}_{\mathrm{I}}\right)$ $0.02 \mathrm{ng} / \mathrm{mL}$, CPK e CPK-MB ns, D-Dimer $678 \mathrm{mg} / \mathrm{dL}$, BNP $37 \mathrm{pg} / \mathrm{mL}]$. In the ED, the patient was started on inhalatory salbutamol, furosemide, steroids and empiric i.v.

C. Mongiardi $(\bowtie) \cdot$ F. Dentali · W. Ageno ·

A. M. Maresca · A. Squizzato · A. Bertolini - A. Venco

Department of Clinical Medicine, University of Insubria,

Varese, Italy

e-mail: mongiardi@gmail.com

E. Verna

Hemodynamic Lab, Department of Cardiology,

University of Insubria, Varese, Italy antibiotic-therapy with piperacillin/tazobactam. An HGA executed $2 \mathrm{~h}$ later, documented resolution of the acidosis and of the hypoxia, clear reduction of the $\mathrm{pCO}_{2}(\mathrm{pH} 7.4$, $\mathrm{pO}_{2} 70 \mathrm{mmHg}, \mathrm{pCO}_{2} 55 \mathrm{mmHg}, \mathrm{sO}_{2} 95 \%$ ). In the afternoon, the patient was transferred to the department of Internal Medicine. About $1 \mathrm{~h}$ after admission, he presented sudden, severe shortness of breath and diaphoresis, the ECG demonstrated sinus tachycardia, a new onset of mild ST segment elevation V3-V6; an HGA showed severe respiratory hypoxic-hypercapnic acidosis $\left(\mathrm{pH} 7.16 \mathrm{pCO}_{2}\right.$ $91 \mathrm{mmHg}, \mathrm{pO}_{2} 56 \mathrm{mmHg}, \mathrm{sO}_{2} 79 \%$ ). IV steroids and inhaled salbutamol were again administered with subsequent resolution of the dyspnea and improvement of gas exchange. Blood tests revealed a mild, initial increase of $T_{I}$ $(0.77 \mathrm{ng} / \mathrm{mL}$ at time $0 \mathrm{~min}, 0.17 \mathrm{ng} / \mathrm{mL} 6 \mathrm{~h}$ later $)$ with persistently normal LDH, AST, and CK. The ECG presented giant and symmetrical negative $\mathrm{T}$-waves in inferiorlateral derivations (D1-D3, V4-V6).

\section{Preliminary diagnosis}

Dr. Squizzato, Prof. Ageno: After cardiologic consultation, on the basis of the ECG abnormalities and a positive marker for myocardial necrosis, therapy with ASA, nitrates and a therapeutic dose of low molecular weight heparin was started. The cardio-thoracic examination was unchanged. A trans-thoracic echocardiogram revealed a mild eccentric left ventricular hypertrophy; a wellpreserved global and segmentary wall-motion (ejection fraction 60\%); an altered diastolic function with a pseudonormalized pattern at color-Doppler and tissue-Dopplerimaging; an absence of tricuspidal regurgitation and a normal systolic pulmonary artery pressure; a high-resistance Doppler flow pattern in the first tract of pulmonary 

tomography scan demonstrates filling defect of the left pulmonary artery $(L P A)$ at the bifurcation between upper and inferior branches compatible with acute pulmonary embolism
Fig. 1 Angio-computed

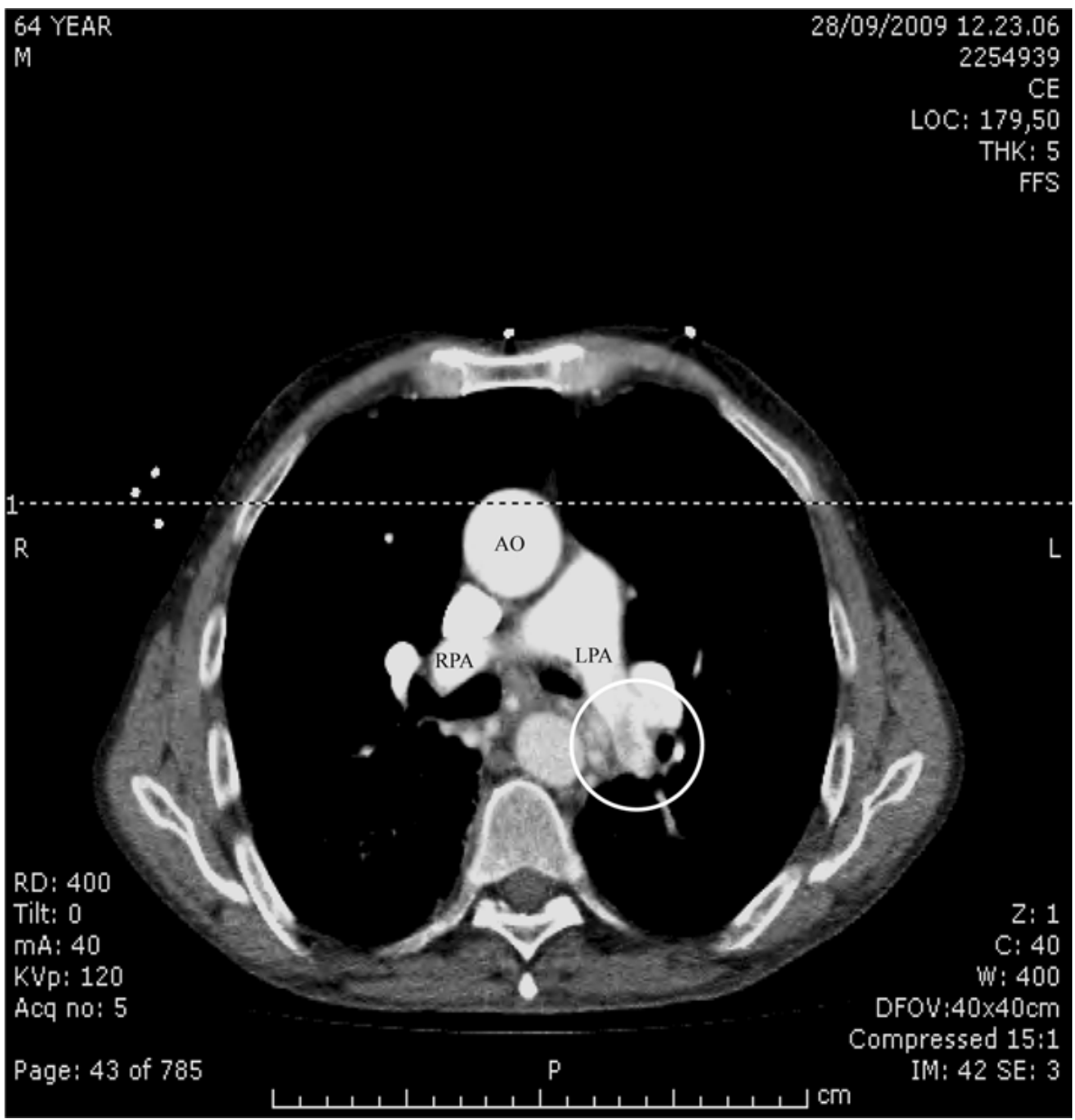

artery and, finally, a mildly enlarged inferior vena cava with preserved collapse during inspiration. An angiocomputed tomography scan was performed, and demonstrated a filling defect of the left pulmonary artery at the bifurcation between upper and inferior branches compatible with acute pulmonary embolism (PE) (Fig. 1). A subsequent ECG showed inferior-lateral ischemic alterations accompanied by ST segment-depression V4-V5 suggestive of an acute coronary syndrome (ACS).

\section{Definitive diagnosis}

Dr. Verna, Dr. Bertolini: A few days later, the patient underwent coronary angiography that revealed the presence of a coronary arterial fistula (CAF) originating from the proximal circumflex coronary artery (the caliber of the aberrant lumen was $5 \mathrm{~mm}$ ) at high-flow with an extended vascular network projecting to the left atrium and opacifying the inferior left pulmonary lobar branches (Fig. 2). The same peripheral artery appeared at this direct angiogram to be involved with an intraluminal filling defect compatible with a peripheral result of pulmonary embolism
(Fig. 3). Selective intra-operatory oxymetry demonstrated an increase in oxygen-saturation of the left pulmonary artery as a further proof of the communication through the fistula. After 5 days, a second coronary angiography was performed, and an Amplatzer ${ }^{\circledR}$ Vascular-Plug-VP4 (8 mm) was placed at the in-flow tract of the CAF. Subsequent angiographic control at $24 \mathrm{~h}$ demonstrated a correct placement and regular expansion of the device with minimal residual aberrant flow through the device. The patient was discharged on oral anticoagulant therapy with vitamin $\mathrm{K}$ antagonists, and had no further complications at a 3-month follow-up. The final diagnosis was acute coronary syndrome due to coronary-pulmonary steal syndrome secondary to pulmonary embolism.

\section{Discussion}

Prof. Venco, Dr. Mongiardi, Dr. Dentali: Acute coronary syndromes (ACS) include a group of clinical conditions caused by myocardial ischemia, namely unstable angina, non-ST-segment elevation myocardial infarction (NSTEMI), and ST-segment elevation myocardial infarction (STEMI). 


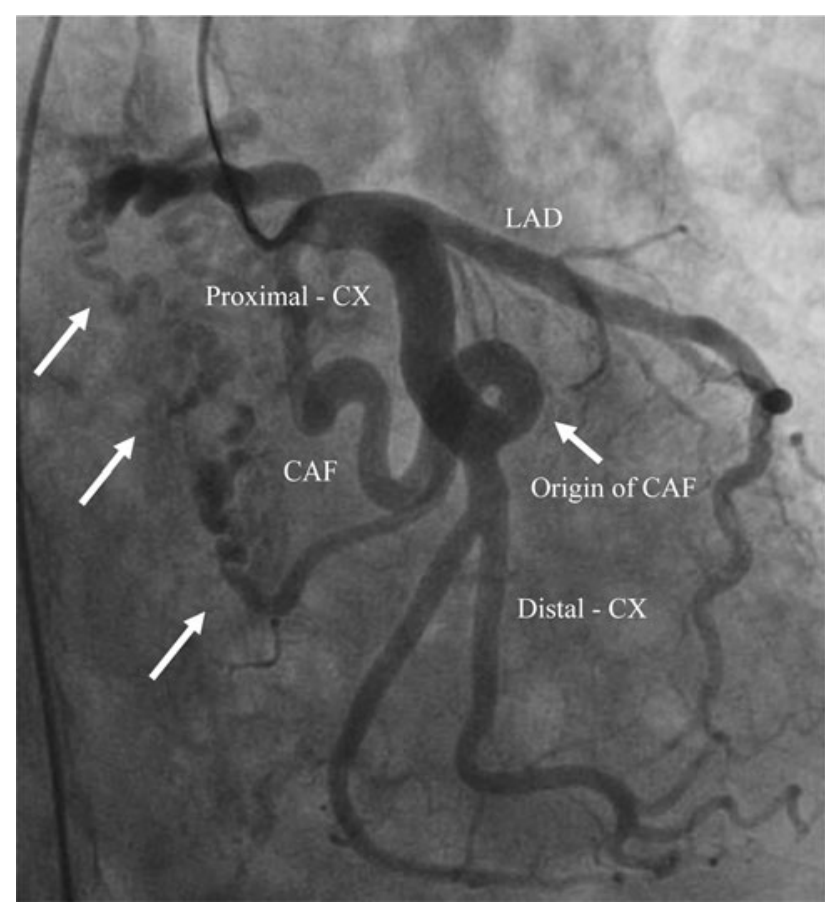

Fig. 2 Coronarography revealed the presence of CAF originating from the proximal circumflex coronary artery (the caliber of the aberrant lumen was $5 \mathrm{~mm}$ ) at high-flow with extended vascular network (arrows on the left) projecting to the left atrium and opacifying the inferior left pulmonary lobar branches

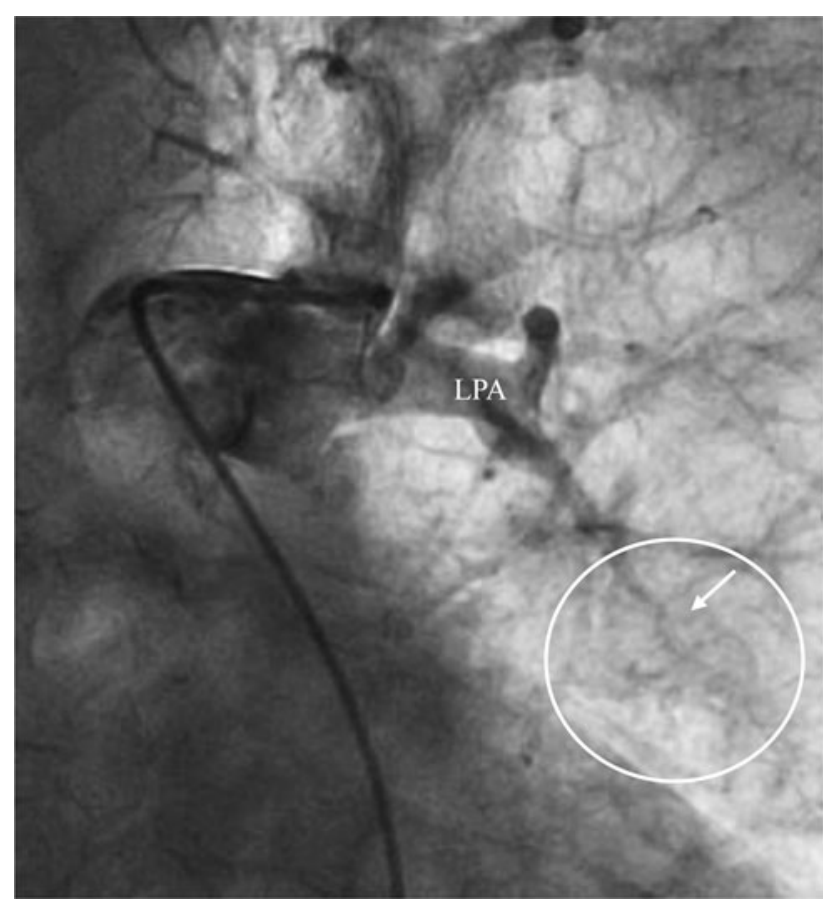

Fig. 3 Direct angiogram showed at the peripheral tract of left pulmonary artery's $(L P A)$ inferior branch the presence of filling defect compatible with peripheral result of pulmonary embolism
Appropriate and accurate diagnosis has life-saving implications, and requires a quick, but thorough evaluation of the patient history, physical examination, electrocardiogram, and cardiac biomarkers [1].

Coronary arterial fistula (CAF) is a connection between one or more of the coronary arteries and a cardiac chamber or a great vessel [2]. The incidence of CAF is unknown, but it has been reported to represent an incidental finding in $0.1-0.2 \%$ of coronary angiograms [3]. The majority of these fistulas are congenital, although they may also occur as a complication of cardiac surgery. In the first two decades of life, they are usually asymptomatic, and a small number of them may close spontaneously [4]. In older subjects, the frequency of CAF-related complications increases, including rupture, thrombosis and embolism of the fistula, dysrhythmias, endocarditis/endarteritis, and, more rarely, congestive cardiac failure and a steal syndrome from the adjacent myocardium [5-8].

In this case report, we describe a steal syndrome from the coronary flow that was attributed to an acquired condition such as an acute PE in a patient with a congenital, asymptomatic CAF.

We hypothesize that the presence of the PE, upstream of the fistula's outflow in the pulmonary artery, determined a redistribution of the pressure gradients between coronary and peripheral pulmonary circulation provoking the ACS. This hypothesis is further supported by the absence of atherosclerotic lesions in the coronary arteries.

The clinical presentation of our patient was rather atypical. Hypercapnia, leucocytosis, and chest X-ray findings may be secondary to an exacerbation of COPD. Conversely, the initial syncopal episode and the in-hospital recurrence of sudden respiratory failure despite appropriate therapy for exacerbation of a COPD were suggestive of an episode of acute PE. COPD is associated with an increased risk for PE [9]. ACS is an uncommon complication in patients with an acute episode of PE. In our case report, the finding of embolization upstream of the fistula's outflow in the pulmonary artery was believed to explain this strange presentation.

Until recently, surgery was the routine treatment for CAFs. Nowadays, transcatheter closure is recommended using a variety of devices, such as occlusion coils, vascular plugs, umbrella devices and covered stents [4, 10-13]. Vascular plugs are generally well tolerated and complications are extremely rare. Due to the concomitant presence of PE, our patient was managed with both anticoagulant therapy and with the placement of an Amplatzer ${ }^{\circledR}$ Vascular-Plug-VP4. In general, secondary prevention of ACS includes antiplatelet therapy. However, in our patient coronary angiography did not reveal any significant abnormality beyond the CAF. Thus, treatment with antiplatelet therapy did not appear to be indicated for the secondary 
prevention of cardiovascular events in our patient. Acute treatment with low molecular weight heparin followed by oral anticoagulation is the mainstay therapy of PE. In this specific case, it seems reasonable that anticoagulation is an effective treatment also to reduce the risk of ACS recurrence since ACS appeared to be due to the coronary-pulmonary steal syndrome.

Conflict of interest None.

\section{References}

1. Kalra S, Duggal S, Valdez G, Smalligan RD (2008) Review of acute coronary syndrome diagnosis and management. Postgrad Med 120:18-27

2. Qureshi SA (2006) Coronary arterial fistulas. Orphanet J Rare Dis $1: 51$

3. Ramos Filho J, Silva OA, Vilarinho DO, Guilherme FG, Ferreira JC, Souza AM (2008) Pulmonary hypertension secondary to coronary to pulmonary artery fistula. Arq Bras Cardiol 91:e19-e21

4. Liberthson RR, Sagar K, Berkoben JP, Weintraub RM, Levine FH (1979) Congenital coronary arteriovenous fistula: report of 13 patients, review of the literature and delineation of management. Circulation 59:849-854
5. Wilde P, Watt I (1980) Congenital coronary artery fistulae: six new cases with a collective review. Clin Radiol 31:301-311

6. McNamara JJ, Gross RE (1969) Congenital coronary artery fistula. Surgery 65:59-69

7. Alkhulaifi AM, Horner SM, Pugsley WB, Swanton RH (1995) Coronary artery fistulas presenting with bacterial endocarditis. Ann Thorac Surg 60:202-204

8. Skimming JW, Walls JT (1993) Congenital coronary artery fistula suggesting a "steal phenomenon" in a neonate. Pediatr Cardiol 14:174-175

9. Rizkallah J, Man SF, Sin DD (2009) Prevalence of pulmonary embolism in acute exacerbations of COPD: a systematic review and metaanalysis. Chest 135:786-793

10. Kassaian SE, Alidoosti M, Sadeghian H, Dehkordi MR (2008) Transcatheter closure of a coronary fistula with an Amplatzer vascular plug: should a retrograde approach be standard? Tex Heart Inst J 35:58-61

11. Liang CD, Ko SF, Lin YJ, Fang CY (2009) Transcatheter closure of a left circumflex coronary artery fistula in two children using the Amplatzer vascular plug. Pediatr Cardiol 130:1172-1175

12. Girona J, Martí G, Betrián P, Gran F, Casaldàliga J (2009) Percutaneous embolization of vascular fistulas using coils or Amplatzer vascular plugs. Rev Esp Cardiol 62:765-773

13. De Santis A, Cifarelli A, Violini R (2010) Transcatheter closure of coronary artery fistula using the new Amplatzer vascular plug and a telescoping catheter technique. J Cardiovasc Med 11:605-609 